\title{
DETERMINAÇÃO DO EXTRATO SECO DE LEITE FERMENTADO, LEITE UHT E CREME DE LEITE: AVALIAÇÃO DE UMA METODOLOGIA SIMPLIFICADA
}

\author{
Frederico Teixeira Corrêa \\ Universidade Federal de Lavras \\ fredericotc01@yahoo.com.br
}

\author{
Patrícia Teixeira Corrêa \\ Universidade Federal de Lavras \\ patteixeiracorrea@gmail.com \\ Luiz Ronaldo de Abreu \\ Universidade Federal de Lavras \\ luizronaldo@dca.ufla.br
}

\section{Resumo}

O extrato seco do leite e de produtos lácteos é uma fração de extrema importância na qualidade e no indicativo nutricional desses alimentos. No caso do leite, o seu valor nutricional e a capacidade de gerar produtos como queijo, iogurte e manteiga são inerentes à fração seca. Objetivou-se na presente pesquisa, avaliar a cinética de secagem e comparar o desempenho de metodologias analíticas, na determinação do extrato seco total em leite UHT integral, creme de leite e leite fermentado. Utilizou-se delineamento inteiramente casualizado (DIC), com três tratamentos e três repetições para cada produto, sendo cada análise realizada em duplicata. As metodologias usadas para o leite UHT foram AOAC (1998), Pereira et al. (2001) e placa de Petri sem areia e sem pérola de vidro. A forma de secagem foi em estufa a $102 \pm 2{ }^{\circ} \mathrm{C}$. Na avaliação dos resultados, foi realizada análise de variância (ANOVA), teste de Tukey ao nível 5\% de probabilidade para resultados significativos nesta análise e construção de curvas de secagem. As diferenças entre as metodologias não foram significativas, indicando que qualquer uma delas pode ser utilizada com segurança na determinação do extrato seco total nos produtos pesquisados. O método da placa de Petri mostrou-se mais eficiente na velocidade de secagem, mais barato e simples de ser executado para pesquisadores e alunos que buscam alternativas em análises laboratoriais.

Palavras-chave: Creme de Leite. Leite Fermentado. Leite UTH Integral. Extrato Seco Total. Metodologias Analíticas.

\section{DETERMINATION OF THE TOTAL SOLIDS OF FERMENTED MILK, UHT MILK, AND MILK CREAM: EVALUATION OF AN SIMPLIFIED METHODOLOGY Abstract}

The milk and dairy products dry extract is a fraction of extreme importance on the quality and nutritional indicative of these meal. In the case of milk, nutritional value and the ability to produce derivatives like cheese, yoghurt and butter are inherent of the dry fraction. The aim of this research, was to evaluate the drying kinetics and compare the performance of different analytical methodologies to determining the total dry extract of whole UHT milk, cream and fermented milk. The experimental design was completely randomized (DIC), with three treatments and three repetitions for each product, being the analysis performed in duplicate. The methodologies used for UHT milk were AOAC (1998), Pereira et al. (2001) and the Petri dish without purified sand and no glass bead. The drying was done in oven at $102 \pm 2{ }^{\circ} \mathrm{C}$. The results was submitted to analysis of variance (ANOVA), regression and the final media of dry extract, Tukey's test for significant results at the level of 5\% probability and the determination of the curves of drying. The differences between the methods were not significant indicating that any of them can safely be used in determining the total solids of the products researched. The Petri dish method was more efficient in drying speed, cheaper and simpler to execute to researcher and students that aim alternatives in lab analysis.

Keywords: Milk Cream. Fermented Milk. Whole Milk. Total Dry Extract. Methodologies.

\section{DETERMINACIÓN DE EXTRACTO SECO DE LECHE FERMENTADA, LECHE UHT Y CREMA DE LECHE: EVALUACIÓN DE UNA METODOLOGÍA SIMPLIFICADA}

\section{Resumen}

El extracto seco de la leche y de productos lácteos es una fracción de extrema importancia en la calidad y en el indicativo nutricional de estes alimentos. En el caso de leche, su valor nutricional y la capacidad de generar productos como queso, yogurt y mantequilla son inherentes a la fracción seca. El objetivo en este trabajo fue evaluar la cinética de secado y comparar la performance de las metodologías analíticas en la determinación del extracto seco total en leche entera UHT, crema de leche y leche fermentada. El diseño experimental utilizado fue el completamente al azar (DCA), con tres tratamientos y tres repeticiones para cada uno de los produtos, siendo las análisis hecha en duplicata. Las metodologías usadas para la leche UHT fueron AOAC (1998), Pereira et al. (2001) y placas de Petri sin arena purificada y sin perlas de vidrio. La forma de secado fue en horno a la temperatura de $102 \pm 2{ }^{\circ} \mathrm{C}$. En la evaluación de los resultados, fue hecha análisis de varianza (ANOVA), test de Tukey para resultados significativos al nivel de $5 \%$ de probabilidad y la contrucción de curvas de secado. Las diferencias entre las metodologías no fueron significativas indicando que cualquier una de ellas puede ser utilizada con seguridad en determinación del extracto seco total de los productos utilizados. El método de la Placa de Petri se mostró más eficiente en la velocidad de secado, más barato y simples de ser ejecutado para investigadores y estudiantes que buscan alternativas en analisis laboratoriales.

Palabras-claves: Crema de Leche. Leche Fermentada. Leche Entera UHT. Extracto Seco Total. Metodologías Analíticas. 
Determinação do extrato seco de leite fermentado, leite UHT e creme de leite: avaliação de uma metodologia simplificada

\section{INTRODUÇÃO}

É notório em ambientes de pesquisa, o custo quase sempre elevado de reagentes, equipamentos e a complexidade na realização de certas análises. Muitas dessas análises demandam tempo e especialização. A busca da simplificação desses processos sem perda de precisão e confiabilidade, é altamente desejável em situação de escassez de recursos.

A umidade ou teor de água de um alimento constitui-se de um importante índice na análise de alimentos. A água pode influenciar na palatabilidade, digestibilidade e no rendimento do produto, além de sua conservação e aptidão tecnológica. A secagem em alimentos é um processo físico o qual a água é removida. Esse conceito também se aplica à operação de evaporação, que é a concentração de soluções líquidas (CELESTINO, 2010).

As dificuldades encontradas na determinação do extrato seco total dos alimentos são: separação de elementos sólidos e líquidos do produto, decomposição de substâncias com mensuração de água acima do valor real, perdas das substâncias voláteis que serão computadas como água e evaporação desuniforme da amostra. Destaca-se ainda o tempo que cada análise despende ao ser realizada e seu custo. A indústria de laticínios apresenta parâmetros bem definidos sobre o teor de extrato seco. Existem vários métodos de análises físico-químicas para leite e produtos lácteos estabelecidos como oficiais, redigidos por órgãos como AOAC, IN68/MAPA, FIL-IDF.

Para a determinação do extrato seco do leite e outros alimentos líquidos, recomenda-se adicionar areia analítica ao recipiente a fim de evitar a formação de bolhas e crostas tornando o processo de evaporação em estufa menos eficiente. A areia analítica distribui o líquido a ser secado no interior do recipiente, evita formação de espuma e aumenta a superfície de contato com o calor, tornando a evaporação mais uniforme. O problema de usar a areia está na dificuldade de sua preparação ou no elevado custo em sua aquisição. No caso das pérolas de vidro normalmente usadas em produtos mais viscosos, sua utilidade é caraterizada por evitar a fervura da amostra e uniformização do calor interior.

De acordo com o mecanismo de transferência de calor predominante no processo, a secagem pode ser classificada como convectiva, condutiva ou radiativa (MILMAN, 2002). Nos alimentos, a secagem não uniforme pode ocasionar a retração linear, além de diferentes tensões no seu interior, que resultarão em bolhas, trincas e rachaduras no produto. É fundamental, para que estes eventos não ocorram que a velocidade ou a taxa de secagem seja controlada (KOSHIMIZU, 2008). 
Determinação do extrato seco de leite fermentado, leite UHT e creme de leite: avaliação de uma metodologia simplificada

Visando fornecer alternativa a pesquisadores e alunos de centros de pesquisa e universidades, que buscam metodologias mais simples e econômicas de se trabalhar, sem perder em confiabilidade dos dados, o presente trabalho teve como objetivo determinar e comparar os resultados obtidos por diferentes metodologias, a matéria seca de leite UHT integral, leite fermentado e creme de leite e suas respectivas cinéticas de secagem.

\section{MATERIAIS E MÉTODOS}

\section{Determinação do extrato seco}

As embalagens consistiram de três marcas diferentes de leite fermentado, leite UHT integral e creme de leite, que foram adquiridas no comércio. As pesagens foram feitas em balança analítica, sendo as embalagens submetidas à homogeneização antes da retirada das alíquotas. $\mathrm{Na}$ secagem, foram observados rigorosamente o controle da temperatura e cuidados para que não houvesse queima das amostras. Em todas as metodologias, tanto as placas de Petri quanto os cadinhos com e sem areia ou pérolas de vidro, foram previamente secos em estufa e deixados esfriar em dessecador. Após a secagem, as amostras ao serem retiradas das estufas, foram colocadas em dessecador, esfriadas e em seguida pesadas. Em todas as metodologias a secagem foi feita em estufa a $102 \pm 2{ }^{\circ} \mathrm{C}$.

Para as metodologias e produtos estudados, as réplicas foram realizadas em série, ou seja, no tempo de retirada do recipiente para pesagem e construção da curva de secagem, o mesmo não retornava para estufa. Houve outro recipiente do mesmo tratamento e da mesma réplica, para mensuração da secagem no tempo subsequente. Esse procedimento foi feito para diminuir erros, evitando a retirada e retorno do mesmo recipiente à estufa. As dimensões e formas dos recipientes estão disponíveis na Figura 1.

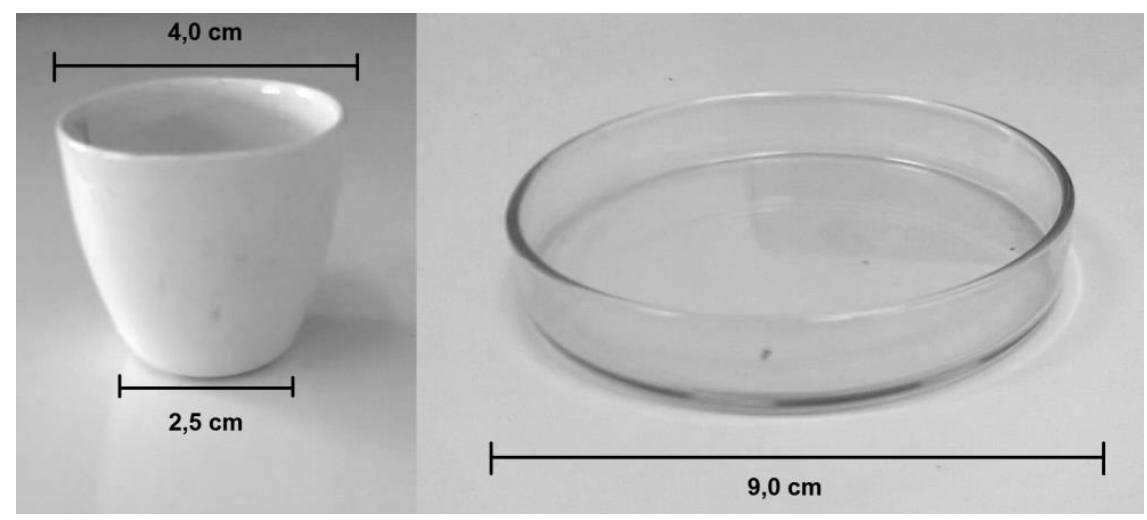

Figura 1: Dimensões e formas dos recipientes utilizados nas análises 
Determinação do extrato seco de leite fermentado, leite UHT e creme de leite: avaliação de uma metodologia simplificada

\section{Leite UHT}

Pelo método AOAC (1998), $5 \mathrm{~g}$ de leite foram coletados para cada determinação. O cadinho (sem areia analítica e pérola de vidro) foi pré-aquecido com a amostra de leite em banho de vapor por 10-15 minutos e em seguida levado à estufa até peso constante entre as pesagens. Pelo método Pereira et al. (2001), foram utilizados cadinhos de porcelana com areia analítica em estufa, mesurando-se os valores até que as pesagens consecutivas apontem valor constante. Pelo método em placa de Petri sem tampa, colocou-se o mesmo peso de amostra em placa de Petri de $9 \mathrm{~cm}$, sem areia analítica e sem pré-aquecimento. Nas placas de Petri, alíquotas de $5 \mathrm{~g}$ de leite foram cuidadosamente espalhadas e rapidamente pesadas na balança de precisão, já que a grande superfície de contato com o ar favorece a evaporação.

\section{Leite fermentado desnatado}

Pelo método Instrução Normativa 68 (BRASIL, 2006), $5 \mathrm{~g}$ de leite fermentado foram coletados para cada determinação. Foram adicionadas pérolas de vidro ao cadinho e levado à estufa até peso constante entre as pesagens. Pelo método Pereira et al. (2001), foram utilizados cadinhos de porcelana com areia analítica em estufa com alíquotas de $5 \mathrm{~g}$ de leite fermentado desnatado. Também foi determinado por método em placa de Petri de $9 \mathrm{~cm}$, sem areia analítica e pré-aquecimento, utilizando-se alíquotas de $5 \mathrm{~g}$ de leite fermentado desnatado que foram cuidadosamente espalhados pela placa e rapidamente pesados.

\section{Creme de leite}

Pelo método descrito na Instrução Normativa 68 (BRASIL, 2006), foram utilizados cadinhos de porcelana com pérolas de vidro e alíquotas de 5g. Pelo método Pereira et al. (2001), foram usados cadinhos de porcelana com areia analítica em estufa. Determinou-se também por método em placa de Petri, com secagem direta em estufa e uso de alíquotas de $5 \mathrm{~g}$, que foram cuidadosamente espalhadas pela placa e rapidamente pesadas. 
Determinação do extrato seco de leite fermentado, leite UHT e creme de leite: avaliação de uma metodologia simplificada

\section{Delineamento experimental e análise estatística}

O experimento foi montado em delineamento inteiramente casualizado (DIC), com três repetições para todos os produtos, sendo três tratamentos para o leite UHT, que se basearam nas metodologias: AOAC (1998); Pereira et al. (2001) (placa de Petri e cadinho de porcelana com areia analítica) e placa de Petri sem areia analítica, com as amostras secas em estufa a $102 \pm 2{ }^{\circ} \mathrm{C}$. Para o leite fermentado e creme de leite, foram feitos três tratamentos baseados nas metodologias AOAC(1998), Pereira et al. (2001), Brasil (2006) e método da placa de Petri sem areia analítica. Cada análise foi realizada em duplicata.

A diferença entre as médias finais do extrato seco total nos tratamentos foram submetidas a análise de variância (ANOVA), em programa computacional SISVAR ${ }^{\circledR}$ (FERREIRA, 2011). Para construção dos gráficos de secagem, calculou-se o número adimensional de umidade (umidade instantânea - umidade de equilíbrio/umidade inicial - umidade de equilíbrio) e os valores obtidos com a secagem, foram ajustados em equação de regressão linear, por meio do programa computacional R (R Development Core Team, 2013). A partir da equação, estimou-se o tempo de secagem para cada tratamento nos produtos estudados.

Para construção do gráfico da cinética de secagem, o peso foi mensurado a cada 15 minutos para cada um dos métodos e em todos os produtos nas cinco primeiras observações. Após a quinta mensuração, a mesma se deu a cada 30 minutos, exceto na metodologia da placa de Petri, que secou na quinta mensuração. Para construção do gráfico, consideraram-se as amostras como secas, quando a diferença de peso entre medições consecutivas foi de até $0,1 \mathrm{~g}$.

\section{RESULTADOS E ANÁLISES}

\section{Cinética de secagem nas diferentes metodologias}

Para análise da matéria seca do leite UHT, foram utilizadas as metodologias AOAC (1998), que se baseou no uso de cadinho e pré-aquecimento em banho-maria, Pereira et al. (2001), com uso de cadinho e areia analítica e placa de Petri, sem areia e sem pré-aquecimento. Como demonstra a Figura 2, as linhas de tendência de secagem referente a cada uma delas, exibem diferentes comportamentos. 
Determinação do extrato seco de leite fermentado, leite UHT e creme de leite: avaliação de uma metodologia simplificada

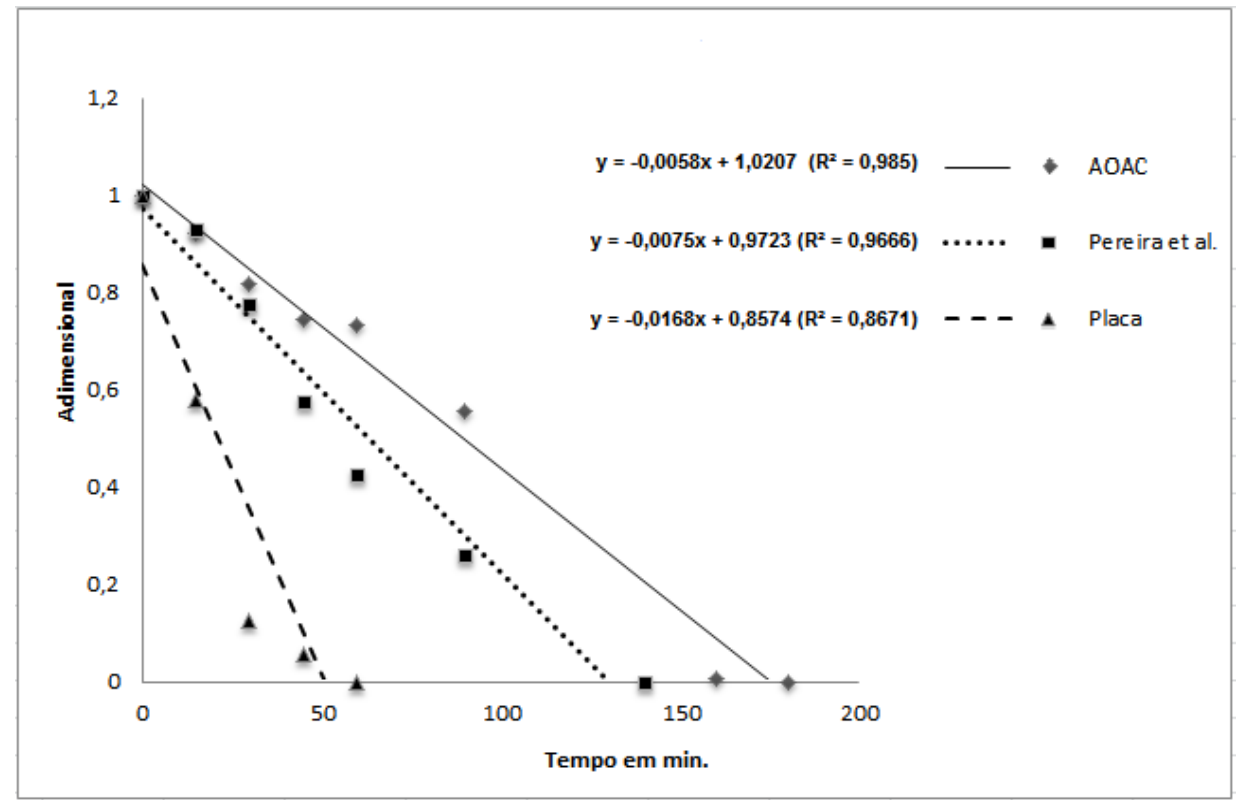

Figura 2: Tempo de secagem em minutos de leite UHT nas metodologias AOAC (1998), Pereira et al.(2001) e placa de Petri.

$\mathrm{Na}$ Figura 2, observa-se através da linha de tendência, que a determinação da matéria seca pela placa de Petri é muito mais rápida, enquanto nas outras metodologias, a linha encontra o eixo X num ponto bem superior, principalmente pela metodologia AOAC (1998). O comportamento das linhas de tendência referentes ao tempo de secagem dos tratamentos AOAC (1998), Pereira et al. (2001) e placa, para o leite fermentado desnatado, pode ser observado na Figura 3.

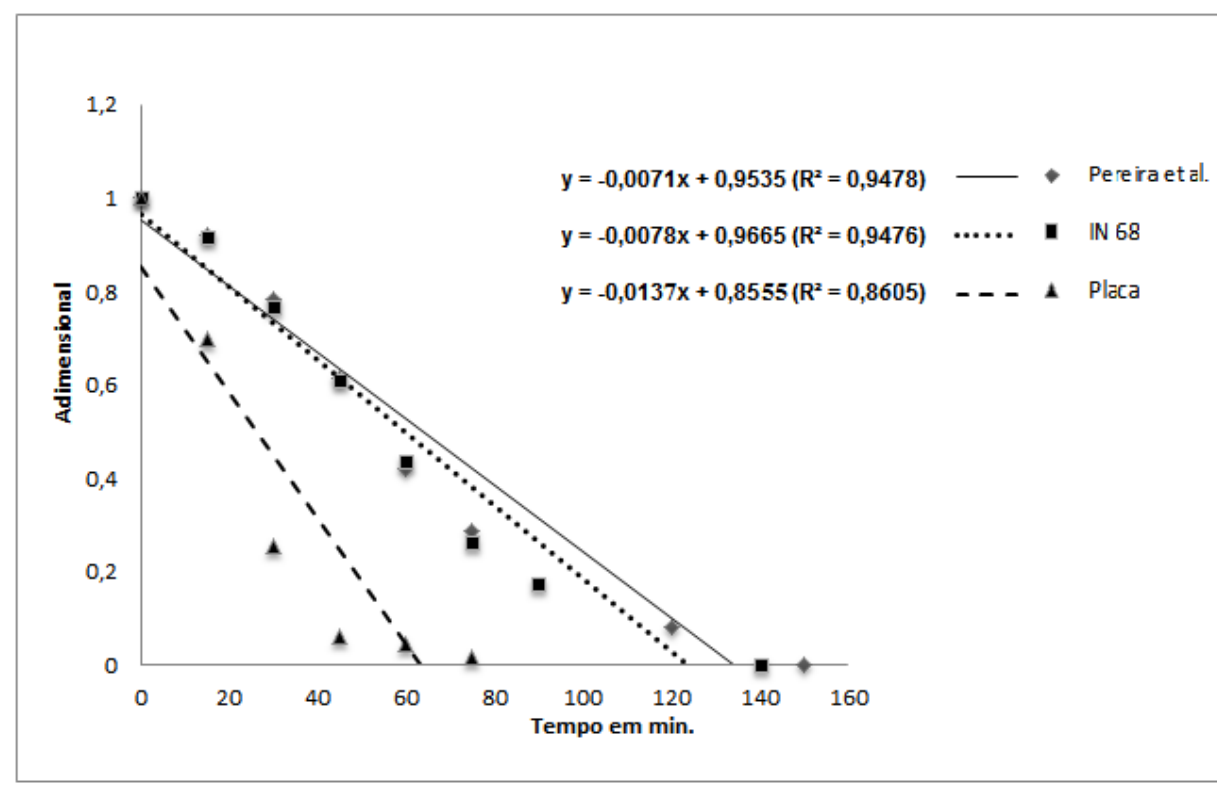

Figura 3: Tempo de secagem em minutos de leite fermentado nas metodologias IN 68, Pereira et al.(2001) e placa de Petri. 
Determinação do extrato seco de leite fermentado, leite UHT e creme de leite: avaliação de uma metodologia simplificada

O comportamento das linhas de tendência referentes à cinética de secagem em creme de leite dos tratamentos AOAC (1998), Pereira et al. (2001) e placa, pode ser observado na Figura 4.

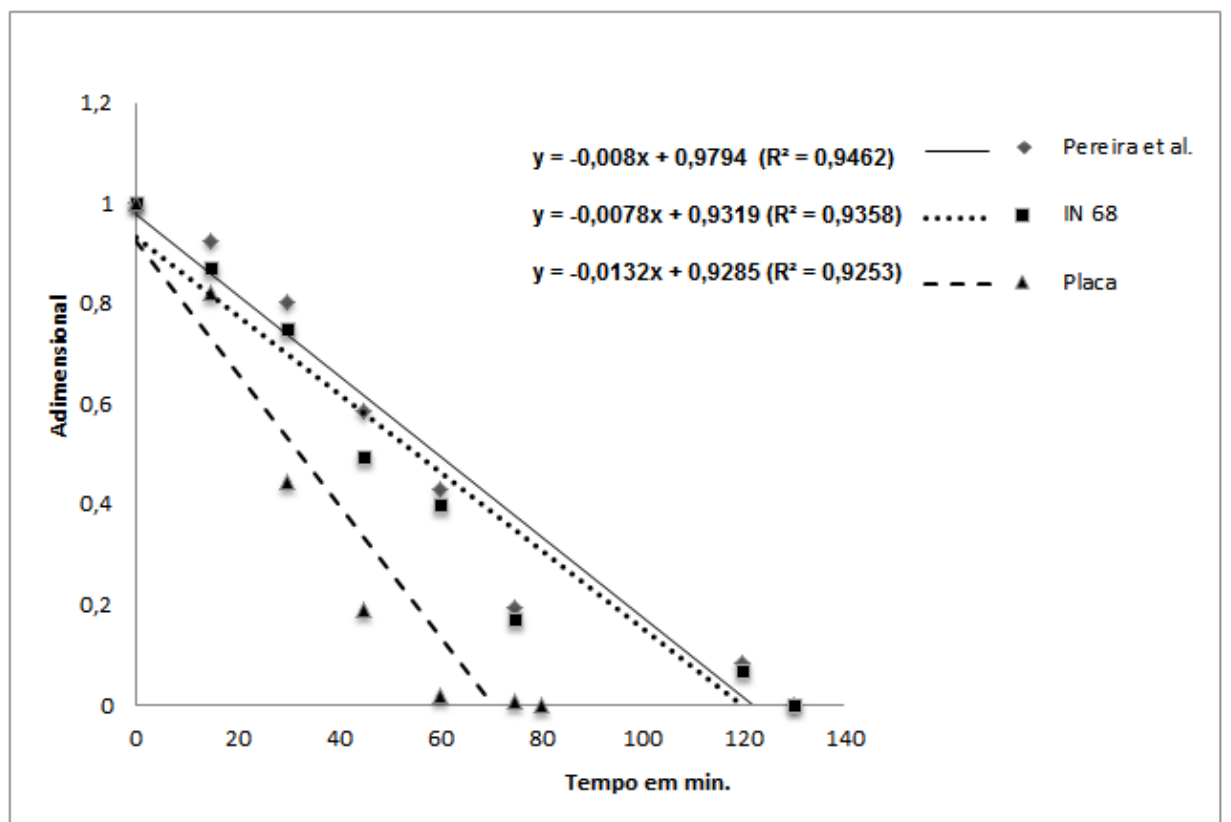

Figura 4: Curva de secagem pelo tempo em minutos, do creme de leite nas metodologias IN 68, Pereira et al.(2001) e placa de Petri.

$\mathrm{Na}$ Figura 2, observa-se que o tratamento caracterizado pela metodologia AOAC apresentou eficiência de secagem bem inferior à metodologia de secagem em placa de Petri. O tratamento Pereira et al., ficou em nível intermediário de eficiência. A maior superfície de exposição ao ar quente favoreceu a secagem na placa de Petri, enquanto que pela metodologia AOAC, além de menor superfície exposta ao ar, ocorreu a tendência de formação de crosta na superfície do leite no momento da secagem. Os coeficiente de determinação para as equações da reta para metodologias AOAC, Pereira et al. e placa de Petri foram respectivamente 0,9850, 0,9666 e 0,8671 indicando boa adequação na estimativa dos valores.

$\mathrm{Na}$ Figura 3, que representa a cinética de secagem do leite fermentado desnatado, os tempos de secagem não foram tão discrepantes entre IN 68, Pereira et al (2001) e placa de Petri quanto as metodologias utilizadas para o leite UHT. Assim como a cinética de secagem do leite UHT, a placa de Petri mostrou-se mais eficiente. Isso ocorreu devido a maior superfície exposta ao ar quente e de evaporação, mostrando que essa metodologia também é mais eficiente para o leite fermentado. Os coeficiente de determinação para as equações da reta para metodologias Pereira et al., IN 68 e placa de Petri foram respectivamente 0,9478, 0,9476 e 0,8605 indicando adequação na estimativa dos valores, principalmente os dois primeiros. 
Determinação do extrato seco de leite fermentado, leite UHT e creme de leite: avaliação de uma metodologia simplificada

Ao analisar a cinética de secagem da metodologia Pereira et al. (2001) e Brasil (2006), fica claro que mesmo essas sendo metodologias acuradas para determinação de matéria seca em leites fermentados, o processo é demorado quando comparado à placa de Petri. Para o creme de leite, no leite UHT e leite fermentado, a placa de Petri mostrou tempo de secagem inferior.

Apesar das três metodologias serem equivalentes na determinação do extrato seco total, a placa de Petri se torna mais interessante do ponto de vista da economia e da simplificação do processo experimental. Tendo em vista que é comum em laboratórios de pesquisa, a realização de grande número de analises, rapidez e precisão são fundamentais. Os coeficientes de determinação para as equações da reta para metodologias Pereira et al., IN 68 e placa de Petri, foram respectivamente $0,9462,0,9358$ e 0,9253 , indicando a melhor adequação na estimativa dos valores.

Diferentes trabalhos disponíveis na literatura explicitam a importância em aperfeiçoar as formas de determinação de nutrientes e qual modelo matemático mais adequado na estimativa dos parâmetros de secagem. Martins et al. (2015) estudando cinética de secagem de folhas de timbó (Serjania marginata Casar) concluíram que o aumento da temperatura promove uma taxa maior de remoção de água nas folhas de timbó durante a secagem, sendo que a equação de Midilli é a que melhor representa a cinética de secagem.

Almeida et al. (2006) avaliando a cinética de secagem em frutos de acerola em secador de leito fixo, com temperatura de 50,60 e $70{ }^{\circ} \mathrm{C}$ e velocidade do ar de secagem de 1,0 e 1,5 m s-1, concluíram que a temperatura é o fator mais influente na secagem.

\section{Médias de extrato seco total nas diferentes metodologias e tempo de secagem}

A análise de variância (ANOVA) indicou que não houve diferença significativa entre as médias de extrato seco final nos diferentes tratamentos para todos os produtos. Os resultados médios de extrato seco total e o tempo de secagem para o leite UHT integral, leite fermentado desnatado e o creme de leite estão disponíveis na Tabela 1. 
Determinação do extrato seco de leite fermentado, leite UHT e creme de leite: avaliação de uma metodologia simplificada

Tabela 1: Médias em porcentagem de extrato seco total (EST) para leite UHT integral, leite fermentado e creme de leite nos diferentes métodos de determinação e estimativa do tempo em minutos segundo as equações de regressão.

\begin{tabular}{|c|c|c|c|c|c|}
\hline Produto & Tratamento & $\begin{array}{l}\text { Médias de } \\
\operatorname{EST}(\%)^{*}\end{array}$ & $\begin{array}{l}\text { Média geral/desvio } \\
\text { padrão }\end{array}$ & C.V. & $\begin{array}{l}\text { Tempo de } \\
\text { secagem** }^{*}\end{array}$ \\
\hline \multirow{3}{*}{$\begin{array}{l}\text { Leite } \\
\text { UHT }\end{array}$} & AOAC & 11,60 & \multirow{3}{*}{$11,65 / 0,13$} & \multirow{3}{*}{1,10} & 175,98 \\
\hline & Pereira & 11,70 & & & 129,64 \\
\hline & Placa & 11,63 & & & 51,03 \\
\hline \multirow{3}{*}{$\begin{array}{l}\text { Leite } \\
\text { ferm. }\end{array}$} & IN 68 & 18,66 & \multirow{3}{*}{$18,63 / 0,23$} & \multirow{3}{*}{1,28} & 123,91 \\
\hline & Pereira & 18,55 & & & 134,29 \\
\hline & Placa & 18,67 & & & 62,40 \\
\hline \multirow{3}{*}{$\begin{array}{l}\text { Creme } \\
\text { de leite }\end{array}$} & IN 68 & 25,33 & \multirow{3}{*}{$25,24 / 0,08$} & \multirow{3}{*}{0,26} & 119,47 \\
\hline & Pereira & 25,18 & & & 122,42 \\
\hline & Placa & 25,21 & & & 70,34 \\
\hline
\end{tabular}

\footnotetext{
*Teste $\mathrm{F}(\mathrm{p}>0,05)$ não significativo para todos os tratamentos

** Estimativa do tempo em minutos, segundo as equações de regressão para cada produto

C.V.: Coeficiente de variação
}

Observa-se na Tabela 1, resultados semelhantes para as médias obtidas em todos os tratamentos para o leite UHT, leite fermentado desnatado e para o creme de leite. O teste $\mathrm{F}$ ao nível de 5\% de probabilidade, não foi significativo em nenhuma observação. Para o leite UHT, a média geral foi $11,65 \%$ de EST. Para o leite fermentado e para o creme de leite, as médias gerais foram 18,63 e $25,24 \%$ respectivamente.

A partir dos resultados é possível inferir, que o método da placa de Petri foi o mais simples e econômico de se trabalhar. Embora todas as metodologias tenham sido eficientes, o método AOAC (1998), Pereira et al. (2001) e Brasil (2006), mostraram-se mais trabalhosos e demorados. As metodologias descritas por Pereira et al. (2001) e Brasil (2006) envolvem o custo na aquisição de areia analítica e pérolas de vidro respectivamente.

No que diz respeito ao tempo de secagem, analisando-se o leite UHT, o tempo pela placa de Petri foi 51,03 minutos contra 129,64 e 175,98 minutos para Pereira e AOAC respectivamente. Foi observada a formação de uma película superficial de gordura nos cadinhos nos instantes iniciais de secagem na metodologia AOAC, o que retardou o processo. No caso do leite fermentado desnatado e creme de leite, a secagem com a placa de Petri foi bem mais rápida como mostrado na Tabela 1. Observa-se também que a secagem do leite fermentado foi mais rápida que o leite UHT integral, provavelmente pelo fato de ser desnatado.

A busca pela forma mais eficiente e econômica de determinar nutrientes é importante não só nas análises de extrato seco em leite e produtos lácteos, mas todos os alimentos. Na revisão 
Determinação do extrato seco de leite fermentado, leite UHT e creme de leite: avaliação de uma metodologia simplificada

realizada sobre o assunto, foi constatado que há pouco estudo visando a melhor forma de determinação da matéria seca em alimentos.

Venturoso et al. (2007), ao pesquisar métodos de determinação de nutrientes de leite e produtos lácteos concluíram que os resultados da análise físico-química de produtos lácteos por metodologia oficial e por ultrassom são semelhantes. Os valores de proteína, gordura, extrato seco desengordurado e densidade obtidos por ultrassom correlacionam-se com os métodos oficiais em soro de queijo, leite e produtos fermentados.

Marcante et al. (2010) ao pesquisarem formas de determinar matéria seca de folhas frutíferas (maracujá, pêssego e abacate) por diferentes métodos de secagem (estufa de circulação de ar forçada regulada a uma temperatura de $70{ }^{\circ} \mathrm{C}$ e o forno micro-ondas), inferiram que os dois métodos testados se aproximam na determinação de matéria seca para as culturas analisadas, mostrando que neste caso, pode-se utilizar o método mais prático e econômico.

Tadini et al. (2012) determinaram matéria seca do leite em micro-ondas e pelas normas AOAC e concluíram que a localização da amostra no prato não interfere significativamente nos resultados da análise. Concluíram também que os valores obtidos no micro-ondas com a potência de 360W e tempo de exposição de 9 ou de 4,5 minutos apresentam valores um pouco distantes do método AOAC.

\section{CONSIDERAÇÕES FINAIS}

Todas as metodologias foram equivalentes em resultado final, na determinação do extrato seco do leite UHT, leite fermentado e creme de leite. O método da placa de Petri sem areia analítica se mostrou mais rápido, econômico e simples de realizar, sendo o mais indicado a pesquisadores e alunos que buscam alternativas em análises laboratoriais. Os gráficos da cinética de secagem demonstraram que o uso da placa de Petri torna a secagem mais rápida. Mais pesquisas na área de ciência dos alimentos no que diz respeito à rapidez e economia na determinação de nutrientes são necessárias, pois existem poucos trabalhos que objetivam pesquisar formas alternativas de determinação de nutrientes em alimentos.

\section{REFERÊNCIAS}

ALMEIDA, C.A.; GOUVEIA, J.P.G.; ALMEIDA, F.A.C.; SILVA, F.L.H. Avaliação da cinética de secagem em frutos de acerola. Rev. de Biol. e Ciênc. da Terra. 2006. 6(1): 145-51. 
Determinação do extrato seco de leite fermentado, leite UHT e creme de leite: avaliação de uma metodologia simplificada

ASSOCIATION OF OFFICIAL ANALYTICAL CHEMISTS (AOAC). Official methods of analysis. 16.(4), Washington: 1998: 3-120.

BRASIL (2006). Instrução Normativa no 68, de 12 de dezembro de 2006. Estabelece métodos analíticos físico-químicos oficiais para leite e produtos lácteos. Diário Oficial da República Federativa do Brasil - Dezembro 2006, (1): 8.

CELESTINO, S.M.C. Princípios de Secagem de Alimentos. Embrapa Cerrados. Planaltina, DF, 2010. 29 p.

FERREIRA, D.F. Sisvar: a computer statistical analysis system. Ciência e Agrotecnologia (UFLA), 2011 Nov; 35(6): 1039-42.

KOSHIMIZU, L. Conformação Viscoplástica por rolos a frio e Caracterização de substratos de alumina. Centro de Ciências Exatas e de Tecnologia. Programa de Pós-Graduação em Ciência e Engenharia de Materias. Universidade Federal de São Carlos - UFSC, São Carlos, SP, 2008.

MARTINS, E.A.S.; LAGE, E.Z.; GONEL ALD FILHO, C.P.H.; LOPES, J.G. Cinética de secagem de folhas de timbó (Serjania marginata Casar) Rev. Bra. de Eng. Agr. e Amb. Campina Grande, PB, UAEA/UFCG, 2015. 19(3): 238-44.

MARCANTE, N.C.; PRADO, R.M.; CAMACHO, M.A.; ROSSET, J.S.; ECCO, M.; SAVAN, P.A.L. Determinação da matéria seca e teores de macronutrientes em folhas de frutíferas usando diferentes métodos de secagem. Ciênc. Rural online, 2010 Nov; 40(11): 2398-401.

MILMAN, M.J. Equipamento para pré-processamento de grãos. Editora e Gráfica Universitária da Universidade Federal de Pelotas - UFPel, Pelotas, RS, 2002. 206 p.

PEREIRA,D.B.C.; SILVA, P.H.F.; COSTA JÚNIOR, L.C.G.; OLIVEIRA, L.L. Físicoquímica do leite e derivados: métodos analíticos. 2. ed. Juiz de Fora: EPAMIG, 2001. 234 p.

R Development Core Team. 2013. R: A language and environment for statistical computing, reference index version 2.13.0. R Foundation for Statistical Computing, Vienna, Austria. www.Rproject.org Acesso em 10 dez. 2015).

VENTUROSO, R.C.; ALMEIDA, K.E.; RODRIGUES, A.M.; DAMIN, M.R.; OLIVEIRA, M.N. Determinação da composição físico-química de produtos lácteos: estudo exploratório de comparação dos resultados obtidos por metodologia oficial e por ultrassom. Rev Bras Cienc Farm 2007 Out; 43(4): 607-13.

TADINI, C.C.; CURI, F.; CARDOSO, A.M. Leite: cálculo de sólidos totais em forno de microondas. Influência da potência, tempo de exposição e localização da amostra. Disponível em http://sites.poli.usp.br/pqi/lea/docs/indlat1997.pdf. Acesso em 11 de jan. de 2016. 